\title{
Planning and management of land use system based on WSR: An analytical framework
}

\author{
$\operatorname{Liyan}^{1 *}$ \\ School of urban management and resource and \\ environment, Yunnan university of finance and \\ economics,Kunming, Yunnan,China \\ liyanyncj@163.com \\ Linli $^{3}$, \\ School of public administration, \\ Nanjing audit university, , Nanjing,Jiangsu,China \\ 648043175@qq.com
}

\author{
Chenzhe , $^{2}$ \\ School of public administration, \\ Nanjing agricultural university, Nanjing,Jiangsu,China \\ chenzhe1703@163.com
}

\begin{abstract}
The WSR methodology of complex system theory is combined with the research of land use system planning and management. Based on WSR methodology, this paper proposes a framework for the planning and management of land use system, and explains the connotation of the three dimensions of land use planning management. In this paper, the specific contents and analysis of physical, rational and human-related aspects in the concrete implementation of land use planning are analyzed. It is proved that the theory and method of land management borrowed from the complexity science is applicable and practical.
\end{abstract}

Keywords-The WSR methodology; Land use system; Land use planning and management

The land use system is an open, dynamic and complex system with multiple factors. Land use planning is an important means of land use system regulation; it's always in a leading position. It is a question of land use management research that how to make land use planning more effective to control the land use system. Wu-li Shi-li Ren-li Approach (WSR) from the development of systematic scientific research is a powerful tool to guide the research of complex systems. Combining it with the land use system, a typical complex system research can help to comprehensively analyze the planning and regulation of land use system. The improvement of traditional land use planning control mode and planning management paradigm will be promoted. This study is based on the perspective of complex systems to review land use system planning and regulation. A framework for the planning and management of land use system is constructed from three dimensions: WSR.

\section{WSR METHODOLOGY AND ITS PRINCIPLES}

Based on western scientific methods and eastern humanistic spirit, WSR is a successful example from the research and practice of a single theoretical method to seek comprehensive and comprehensive management effect and management process. The definition of WSR is that "W" refers to the objective existence that people face in dealing with a system project and problem processing, and it is the law of physical movement. "S" refers to the mechanism involved in dealing with the objective existence and regularity of a system project and problem processing. "R" refers to the relationship between all the people involved in a system project and problem processing, and the process of change. The philosophical basis of the WSR methodology emphasizes that social situations consist of things, things and people. Therefore, any project dealing with this kind of events should take into consideration the three elements of physics, reason and humanity from the perspective of functional integrity.

\section{THE PLANNING AND CONTROL OF LAND USE SYSTEM}

\section{BASED ON WSR METHODOLOGY}

Based on WSR methodology, combining the characteristics of land use system natural, social attribute, self-organization and his organization way are coupled, according to the train of thought that understanding majorization - management, the analysis framework is constructed from three dimensions: system evolution, planning control and tracking management.

\section{A.d frame and theoretical interpretation}

1) The dimension of $W$ - System evolution and status evaluation

The dimension of $\mathrm{W}$ focus on the objectivity of ontology. It includes the physical environment and structure, containing natural or social, concrete, or abstract aspects. The study of physics focuses on investigation, analysis, and knowledge of the objective physical world. In the face of land use system planning and regulation, the physical dimension is to achieve "a clear mind and a clear picture" , First of all, it is necessary to make clear the theoretical method needed in the process of controlling land use system. Non-linear science, ecological economics, systems engineering and complexity science constitute the "toolbox" for analyzing the structure, function and evolution mechanism of land use system. On the basis of these theoretical methods, the characteristics, structure, function and evolution mechanism of land use system and the objective evaluation of the system state are explained. Grasp of the "physical” including understanding of regional land resources quantity, types and distribution characteristics of soil, climate, hydrology and related data, population, social economic conditions and at different levels of organization and structure of land use system and so on. Because the regional land use system has typical regional differentiation characteristics, the land resource endowment of different regions is different, and the structure and function of each subsystem of land use system are different. Clear widely 
known regional population growth and economic development the demand for land use, must understand the characteristics of the evaluation objects, established in accordance with the specific evaluation goals can characterize the evaluation index system of evaluation object properties, detailed and comprehensive as possible, to collect the relevant information and original data, so as to determine the parameter values, rational evaluation results are obtained. This level focuses on the use of philosophical thinking to answer the question of "what" according to the system theory.

\section{2) The dimension of $S$ - Plan formation and decision
making}

The dimension of $\mathrm{S}$ focus on the decision and intervention of the system based on human will. For land use system planning and regulation, the core task of the problem is how to determine the optimal allocation plan of land use system. It contains two main contents: land use structure optimization and land use space layout. In the decision-making process, "elastic index and scheme comparison" are implemented. To complete this core task, we must choose the appropriate technical method to establish the optimization model. The model should not only restore the self-organizing feature of the system, but also reflect the multi-objective coordination of planning and regulation, and also meet the multi-program demand of dynamic programming. So, The key to the optimization model lies in the evolution mechanism of land use system, Attaches great importance to the factors influencing the fluctuation of land use system, through the study of the demand forecasting of regional land use and benefit analysis, to set the parameters of the model, reasonable determination of the objective function of optimization model and constraint condition, and implement the elements of the land use system of the linear and nonlinear relation between paint effectively. On the basis of determining reasonable land use structure, the land use system is adjusted according to the overall benefit of land use system. The regulation of the regional land use system must be based on the whole system of the regional complex system, focusing on the macro structure and function of the system, and implementing the overall coordination and process control. This level focuses on the use of logical thinking to solve the problem of "how to do" according to the technical method of system engineering.

3) The dimension of $R$ - Public participation and planning for dynamic tracking

The dimension of " $\mathrm{R}$ " focus on the subjective relationship between all the stakeholders involved in the system. In the process of land use system regulation, the key question of the research is whether it can meet the value orientation of the stakeholders involved in the planning. The dimension of $\mathrm{R}$ is to explore the self-organization management approach of land use system based on conflict analysis, interest game research and man-machine interaction. Finally, through "policy innovation, tracking management" to ensure the smooth and effective implementation of the plan. Land use system planning and regulation involves the interests of the country, local government, community residents, and farmers and so on. This requires the expression of interest, intention and motivation of these stakeholders in system design and implementation. Planning regulation should not only reflect the dominant consciousness of national land use management, but also can coordinate the relationship between the interests of stakeholders in the process of land use, pay attention to the specialists and the public opinion in the process scheme of phase synthesis. The main role of men and related interests in the course of the land use system evolution is to through the land management system and the design of the supporting measures to protect the implementation of planning and interests in the process of this regulation. This level focuses on the use of management thinking and means, mainly relying on system design and policy implementation to solve the "how to do better" problem?

\section{B. Specific implementation process}

The general working steps of land use planning under the guidance of WSR system methodology are divided into the following seven steps: (1)Systematic investigation; (2) System analysis; (3) System evaluation; (4) System optimization; (5) plan implementation; 6) Plan adjustment; (7) Implement and feedback loops.

Explore the solve the problem of land use system, not only from the local analysis and diagnosis, and should consider both the state of the land use system evolution and physical level, and to consider how to better use, control the reasonable level, at the same time also need to consider in the process, how people involved, how to understand problems and deal with the problem and implement decisions management. Therefore, in general, the process of land use system planning and regulation is also the process of seeking physical, logical and human coordination. In the different stages of land use system planning and regulation of the system engineering, the physical, logical and human factors correspond to different aspects of the planning. So, the system of land use planning regulation in the physical, things, and one for independent research, or system integration is necessary to study, the more you know about their respective features, for they constitute the overall the more they know; And vice versa.

In the early stage of the planning, in order to objectively master planning regional condition, the basis of the natural, social and economic conditions for a comprehensive range of data collection, the entire process tend to the understanding of the physical properties, planning area of land use system itself evolution and status of objective evaluation; While in the planning stage, according to the regional social and economic development goals, the development of the industry land demand and objective restrictions, with the help of mathematics and computer properly optimized configuration scheme of land use system, the process is under the guidance of rational target in accordance with the will of people to solve the problem "how to do"; In the planning and implementation phase, the more emphasis will be on human performance. In the planning and implementation of all kinds of system arrangement, the interests of the coordination of planning implementation effect has a direct impact, at this stage, the excluded from technical factors, the reason produced a dominant force.

On the other hand, the whole process of land use system planning is interwoven with the physical, rational and human relations, which cannot be separated. Although the physical, rational and ethical aspects of the planning have different emphasis on each link, they are still reflected in the whole process of planning. Especially, the land use system is a controllable social and economic system, people to adjust and control of the controlled system is the essential purpose of serving the people, therefore, the reason is the fundamental rules of power control system. It is a process of systematic analysis and rational decision making that understanding physics and understanding reason belongs to rational cognitive function, and the key needs the support of 
technology ; It is a process of interest adjustment and organization management, and it depends on the guarantee of the system. In a word, the coordination between physical, rational and human beings is embodied in the coordination of the organization and land use planning of the land use system.

\section{CONCLUSIONS}

The study combines WSR methodology with land use system planning and management, which is the reference and intersection of system engineering theory in land management discipline. The research shows that the WSR methodology and land use system planning and management can be highly coordinated and integrated, which is helpful for the improvement of land use planning theory system in China. This paper proposes a framework of land use system planning and management based on WSR methodology, it expounds the connotation of the three dimensions of land use planning management, the specific contents and analysis of physical, rational and human factors in the concrete implementation of land use planning are analyzed. Through the research, this paper puts forward a systematic comprehensive analysis of land use system planning and management, the three aspects of system evolution and state evaluation, planning scheme formation and decision making, public participation and planning and implementation of dynamic tracking are composed of the WSR 3d frame of land use system planning and management.

But the downside is that this study only proposed the analysis framework of land use planning management under the guidance of WSR methodology, which is limited to the scope of theoretical research. In the follow-up study, it is necessary to extend the method transplantation on the basis of theoretical reference.

\section{ACKNOWLEDGEMENT}

Express my sincere thanks to professor wang wanmao for his inspiration and guidance.

\section{REFERENCE}

[1] CAI yumei, Deng hongdi. Analysis on the trend of land use planning in China [J]. Land science dynamics, 2010, 2(2).

[2] Feng wenli. Research on public participation in land use planning [J]. Chinese land science.2003(17).

[3] GU J F, Zhu z c. The Wu-li Shi-li Ren-li Approach(WSR):an Oriental Methodology, in Systems Methodology: Possibilities for cross-cultural Learning and Integration(G. Midgley and J. Wilby eds.),The University of Hull Press, United Kingdom, 1995.

[4] Liu yongqing, zhang guangyu. On land use system engineering -principles, methods and systems [J]. Systems engineering,1997,15(2).

[5] R. F. Steiner and H. W, Vanlie, Land Conservation and Development-Examples of Land Use Planning Projects and Programs, Printed in the Netherlands.1984.

[6] Reuben N.Weisz. A system analysis approach to land use Planning [M].National technical information service.1977.

[7] Sharifi, Van Keulen H; A decision support system for land use planning at enterprise level [M]; Agricultural Systems; 1994.

[8] Wu xiaojun, xue huifeng. Complexity theory and application in urban system research $[\mathrm{M}]$. Xi 'an: northwest university of technology press.2007. 